Open Access

\title{
Deletion of NIrp3 protects from inflammation-induced skeletal muscle atrophy
}

Nora Huang ${ }^{1,2+}$, Melanie Kny ${ }^{1 \dagger}$, Fabian Riediger ${ }^{1,3+}$, Katharina Busch ${ }^{1}$, Sibylle Schmidt ${ }^{1}$, Friedrich C. Luft ${ }^{1,4}$, Hortense Slevogt ${ }^{5,6}$ and Jens Fielitz ${ }^{1,2,4^{*}}$

\begin{tabular}{l}
\hline${ }^{*}$ Correspondence: \\
jens.fielitz@charite.de \\
${ }^{\dagger}$ Equal contributors \\
${ }^{1}$ Experimental and Clinical Research \\
Center (ECRC), \\
Charité-Universitätsmedizin Berlin, \\
Max Delbrück Center (MDC) for \\
Molecular Medicine in the \\
Helmholtz Association, Berlin, \\
Germany \\
${ }^{2}$ Department of Cardiology, Heart \\
Center Brandenburg and Medical \\
University Brandenburg (MHB), \\
Bernau, Germany \\
Full list of author information is \\
available at the end of the article
\end{tabular}

* Correspondence:

ens.fielitz@charite.de

Center (ECRO),

Charité-Universitätsmedizin Berlin,

Max Delbrück Center (MDC) for

Molecular Medicine in the

Germany

²Department of Cardiology, Heart

Full list of author information is

available at the end of the article

\begin{abstract}
Background: Critically ill patients develop atrophic muscle failure, which increases morbidity and mortality. Interleukin-1 $\beta(I L-1 \beta)$ is activated early in sepsis. Whether IL$1 \beta$ acts directly on muscle cells and whether its inhibition prevents atrophy is unknown. We aimed to investigate if IL-1 $\beta$ activation via the Nlrp3 inflammasome is involved in inflammation-induced atrophy.

Methods: We performed an experimental study and prospective animal trial. The effect of IL-1 $\beta$ on differentiated C2C12 muscle cells was investigated by analyzing gene-and-protein expression, and atrophy response. Polymicrobial sepsis was induced by cecum ligation and puncture surgery in Nlrp3 knockout and wild type mice. Skeletal muscle morphology, gene and protein expression, and atrophy markers were used to analyze the atrophy response. Immunostaining and reportergene assays showed that IL-1 $\beta$ signaling is contained and active in myocytes.

Results: Immunostaining and reporter gene assays showed that IL-1 $\beta$ signaling is contained and active in myocytes. IL-1 $\beta$ increased $/ 16$ and atrogene gene expression resulting in myocyte atrophy. Nlrp3 knockout mice showed reduced IL-1 $\beta$ serum levels in sepsis. As determined by muscle morphology, organ weights, gene expression, and protein content, muscle atrophy was attenuated in septic Nirp3 knockout mice, compared to septic wild-type mice $96 \mathrm{~h}$ after surgery.
\end{abstract}

Conclusions: $\mathrm{IL}-1 \beta$ directly acts on myocytes to cause atrophy in sepsis. Inhibition of IL-1 $\beta$ activation by targeting Nlrp3 could be useful to prevent inflammation-induced muscle failure in critically ill patients.

Keywords: Sepsis, IL-1ß, Muscle weakness, ICUAW

\section{Background}

A major contributor of intensive care unit (ICU)-acquired weakness (ICUAW) is a severe and disabling muscle atrophy leading to loss in strength and mass [1-4]. ICUAW is associated with increased morbidity and mortality and has a significant impact on healthcare systems $[5,6]$. Sepsis and systemic inflammation are major risk factors for ICUAW $[7,8]$. Importantly, inflammation and acute-phase response occur early and directly in muscle and affect disease progression in ICUAW. Recently, others and we reported an imbalanced protein homeostasis caused by increased protein degradation 
and reduced protein synthesis in the skeletal muscle [4, 9-11]. Muscular-motor protein breakdown, especially myosin heavy chain $(\mathrm{MyHC})$, via the protein degrading ubiquitin proteasome system (UPS), is a prominent feature of muscle atrophy [1, 4, 10-13]. The E3 ligase, muscle RING finger (MuRF) 1 (TRIM63), and F-box protein atrogin 1 (FBXO32) are increased in muscle during atrophy and mediate degradation of structural proteins $[4,10]$. Interleukin- $1 \beta(\mathrm{IL}-1 \beta)$ is one of the most activated cytokines in sepsis [14-20]. In muscle, IL-1 $\beta$ increases MuRF1 and atrogin 1 expression implicating a function in atrophy [21-23]. However, if IL-1 $\beta$ directly causes muscle atrophy in sepsis and if inhibition of IL-1 $\beta$ prevents this response is unknown. IL-1 $\beta$ production and secretion requires three consecutive steps that are tightly controlled, namely expression, cleavage, and secretion. Whereas inflammatory cytokines increase expression of pro-IL-1 $\beta$, which is the inactive proform of IL- $1 \beta$, its conversion to IL- $1 \beta$, and its secretion is mediated by caspase- 1 activating inflammasomes [14, 24-28]. Inflammasomes are multi-protein complexes of the innate immune system [29] and involved in the pathogenesis of sepsis [30]. Cytoplasmic receptors of the nucleotide binding domain (NOD)-like receptor (NLR) family are key components of the inflammasome, of which the best characterized NLR is NLRP3 [31, 32]. The NLRP3 inflammasome regulates maturation and secretion of IL-1 $\beta$ [32]. IL-1 $\beta$ signal transduction occurs via the IL-1 receptor, which is associated with IL-1 receptor-associated kinase 1 (IRAK1) that activates the transcription factor nuclear factor-kappa B (NF-kB) [33]. NLRP3 is contained in muscle, and its activity is increased in myopathies [34]. However, the function of NLRP3 and IL-1 $\beta$ in ICUAW is unknown. We tested the hypothesis that IL-1 $\beta$, depending on the Nlrp3 inflammasome, contributes to inflammation-induced atrophy in vitro and in vivo.

\section{Methods}

Animal model

Animal procedures were performed in accordance with the guidelines of the MaxDelbrück Center for Molecular Medicine, were approved by the Landesamt für Gesundheit und Soziales, Berlin, Germany (G207/13, G129/12), and followed the "Principles of Laboratory Animal Care" (NIH publication No. 86-23, revised 1985) and the current version of German Law on the Protection of Animals. Nlrp3 knockout (KO) mice were kindly provided by Aubry Tardivel and Nicolas Fasel (University of Lausanne) [35]. Cecal ligation and puncture (CLP) surgery was performed to induce polymicrobial sepsis in 12- to 16-week-old male Nlrp3 $\mathrm{KO}$ or wild-type (WT) mice as recently described [36-38]. Sham mice were treated identically except for the ligation and puncture of the cecum. Mice were sacrificed $96 \mathrm{~h}$ after surgery. For more information, see Additional file 1.

\section{Molecular and cell biology analysis}

For detailed information about quantitative RT-PCR (qRT-PCR), western blotting, immunostaining, and cell culture, see Additional file 1 . Measurements of serum IL-1 $\beta$ were performed by using the Mouse ELISA Kit for IL-1 $\beta$ (Abcam, ab100704) according to the manufacturers' protocol. 


\section{Statistical tests}

All experiments were performed independently and at least three times using biological triplicates each. All qRT-PCR gene expression data from mouse and cell culture samples was analyzed by one-way ANOVA with post hoc correction (Tukey's postcomparison test). Paired $t$ test was used to study the distribution of myotube diameter in $\mathrm{C} 2 \mathrm{C} 12$ myotubes. Survival curves were compared with a Mantel-Cox test. Differences were considered statistically significant at $p<0.05$. Data are shown as mean \pm standard error of the mean (SEM) in bar plots. Plots and statistics calculation were done by using the GraphPad Prism ${ }^{\circledast} 6$ program (GraphPad Software, La Jolla, CA, USA), Adobe Illustrator CS6, version 16.0.0, and Photoshop CS6, version 13.0. The documentation of immunofluorescence and histological staining results was performed with a Leica fluorescence microscope using Leica cameras (DFC 360 FX and DFC 425) and the LAS.AF software (version: 2.4.1 build 6384 and the LAS3.1 software (version 2.5.0.6735).

\section{Results}

\section{IL-1 $\beta$ induces myocyte atrophy in vitro}

Recently, we showed that inflammation and acute-phase response participates in the pathogenesis of ICUAW in patients [10]. However, whether IL-1 $\beta$ is synthesized in muscle and whether Nlrp3-mediated IL-1 $\beta$ maturation is involved in inflammationinduced atrophy was unknown. We performed qRT-PCR to investigate if sepsis increases $I l 1 b$ or Nlrp3 expression in gastrocnemius/plantaris or tibialis anterior muscle of mice and found that sepsis induced $I l 1 b$ and Nlrp3 expression in both muscles (Additional file 2A, B). Il6 expression was also induced. These data indicate that IL-1 $\beta$ and Nlrp3 are contained and activated in muscles during sepsis.

To investigate if the IL-1 $\beta$ signaling pathway is contained and active in myocytes, we analyzed cytoplasmic-to-nuclear translocation of IL-1 receptor type I (IL-1R1) associated kinase 1 (IRAK-1) in $\mathrm{C} 2 \mathrm{C} 12$ muscle cells. C2C12 myoblasts were originally isolated from wild-type mice [39] and selected for its ability to differentiate to myotubes expressing characteristic muscle proteins [40]. Others [41-43] and we [36, 38, 44] have used this cell line earlier to investigate mechanisms of inflammation-induced myocyte atrophy. Using immunocytochemistry, we found that $30 \mathrm{~min}$ of IL-1 $\beta$ treatment resulted in an increased cytoplasmic-to-nuclear shift of IRAK-1 in C2C12 myocytes (Fig. 1a) indicating that the IL-1 $\beta$ pathway is active in myocytes. Since IL- $1 \beta$ mediates its effects via NF- $\mathrm{kB}$ in non-myocytes, a luciferase reporter assay was used to test if this response also occurs in myocytes. The same assay performed in HeLa cells was used as positive control. IL-1 $\beta$ treatment induced the NF- $k B$ promoter in muscle and nonmuscle cells (Fig. 1b), indicating that IL-1 $\beta$ activates NF- $\kappa B$ dependent signaling events in muscle cells. To test if IL- $1 \beta$ induces its target genes in myocytes, we treated $\mathrm{C} 2 \mathrm{C} 12$ myotubes with recombinant IL-1 $\beta$ for different time points and quantitated 16 expression (Fig. 1c). IL-1 $\beta$ induced Il6 and Nlrp3 expression in myocytes after $2 \mathrm{~h}$ of treatment (Fig. 1c, d). Together, these data indicate that the IL-1 $\beta$ pathway is functional in myocytes. To investigate if IL- $1 \beta$ induces myocyte atrophy, we treated $\mathrm{C} 2 \mathrm{C} 12$ myotubes with increasing amounts of recombinant IL-1 $\beta$ and vehicle, respectively, for $72 \mathrm{~h}$ and measured myotube diameters. IL-1 $\beta$ treatment caused a significant reduction of myotube diameters after $72 \mathrm{~h}$ (Fig. 1e). Frequency distribution histograms of myotube 


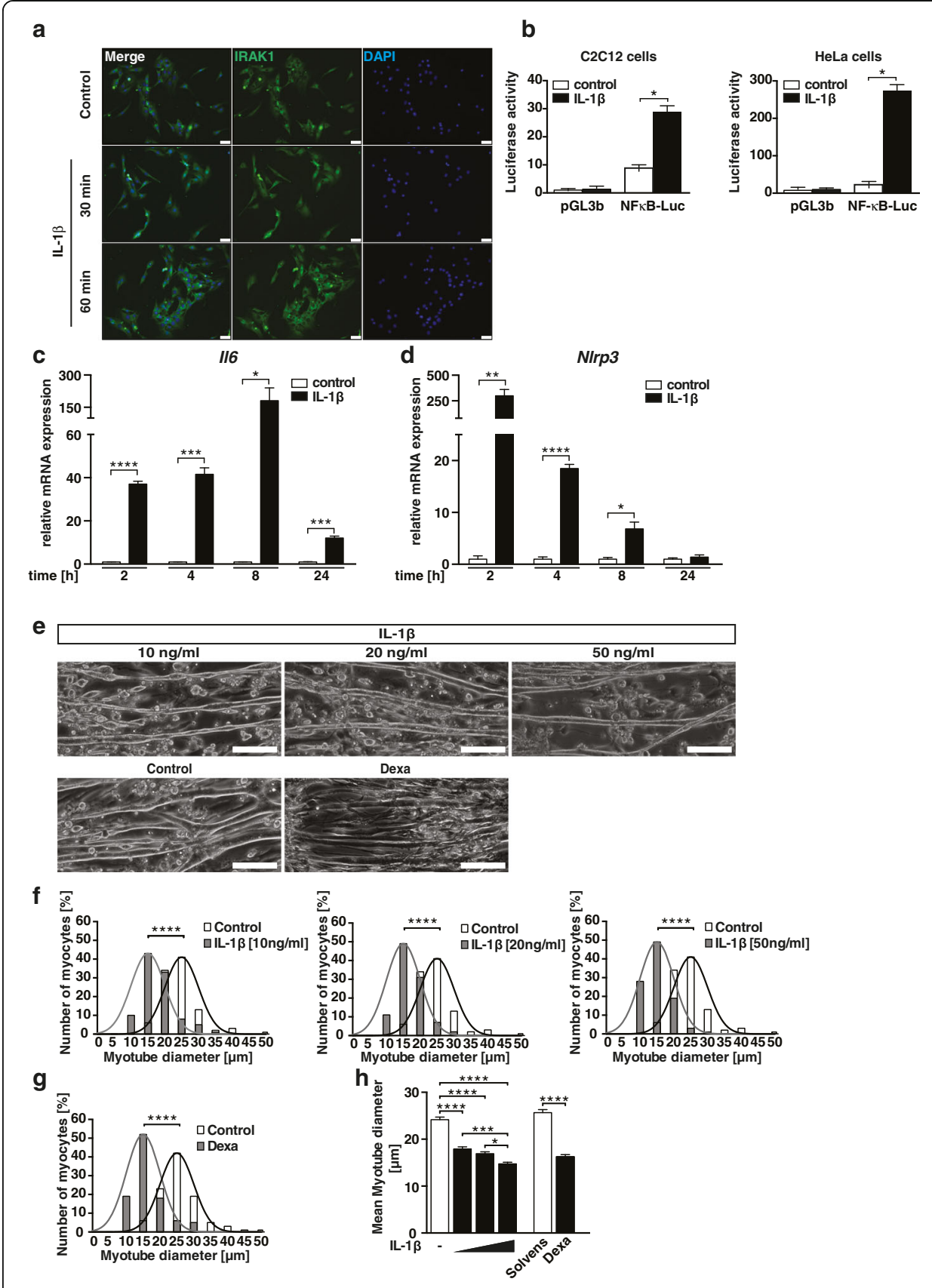

Fig. 1 (See legend on next page.) 
(See figure on previous page.)

Fig. 1 The IL-1 $\beta$ signaling pathway is contained and active in $\mathrm{C} 2 \mathrm{C} 12$ myocytes. a $\mathrm{C} 2 \mathrm{C} 12$ muscle cells were treated with human recombinant IL-1 $(10 \mathrm{ng} / \mathrm{ml})$ or vehicle for $30 \mathrm{~min}$ and $1 \mathrm{~h}$. Immunocytochemistry with anti-IRAK1 antibody shows cytoplasmic-to-nuclear translocation of IRAK1 in response to IL-1 $\beta$ after $30 \mathrm{~min}$. Nuclei were stained in blue (DAPI). Scale bar $=50 \mu \mathrm{m}$. b Synthetic luciferase reporters with multimerized NF-KB sites (NF-KB-Luc) were transfected into C2C12 (b, left panel) and HeLa (b, right panel) cells, together with LacZ as transfection control. Cells were treated with recombinant IL-1 $\beta(10 \mathrm{ng} / \mathrm{ml})$ for 24 h. $n=3$. c $\mathbf{d}$ C2C12 cells were differentiated for 8 days and treated with human recombinant IL-1 $\beta$ $(10 \mathrm{ng} / \mathrm{ml})$ for different time points as indicated. qRT-PCR analysis of $1 / 6$ and N/rp3. mRNA expression was normalized to Gapdh. All data are reported as fold change \pm SEM. e-h $\mathrm{LL}-1 \beta$ increases N/rp3 expression and induces atrophy in differentiated $\mathrm{C} 2 \mathrm{C} 12$ myocytes in vitro. $\mathrm{C} 2 \mathrm{C} 12$ cells were differentiated for 8 days and treated with human recombinant IL-1 $(10,20$, and $50 \mathrm{ng} / \mathrm{ml})$ for $72 \mathrm{~h}$. Dexamethasone $(10 \mu \mathrm{M} / \mathrm{ml})$ treatment was used as atrophy control. e Representative light microscopy pictures. Scale bar $=250 \mu \mathrm{m}$. f, $\mathbf{g}$ Frequency distribution histograms of cell width of $\mathrm{IL}-1 \beta(10,20$, and $50 \mathrm{ng} / \mathrm{ml})$ and dexamethasone-treated myotubes, as indicated, compared to vehicle-treated myotubes, $n=100$ cells per condition. $\mathbf{h}$ Mean myotube width. Data are presented as mean \pm SEM. ${ }^{*} p<0.05,{ }^{* *} p<0.01,{ }^{* * *} p<0.001,{ }^{* * * *} p \leq 0.0001$

diameters showed a dose-dependent increase in the number of thinner myotubes resulting in a leftward shift of the histogram and a dose-dependent decrease in mean myotube diameters after $72 \mathrm{~h}$ of treatment (Fig. 1f, h). Dexamethasone (Dexa), which was used as positive control, resulted in myotube atrophy after $72 \mathrm{~h}$ (Fig. 1e, g, h).

Because a reduction in $\mathrm{MyHC}$ proteins is consistently observed in inflammationinduced atrophy $[1,10]$, we investigated if IL- $1 \beta$ causes a reduction in MyHC protein. $\mathrm{C} 2 \mathrm{C} 12$ myotubes were treated with recombinant IL-1 $\beta$ and vehicle, respectively, for $72 \mathrm{~h}$ and Western blot was performed. Indeed, IL-1 $\beta$ decreased fast and slow MyHC protein contents (Fig. 2a). As expected, Dexa treatment caused a reduction in slow and fast MyHC contents after 72 h (Fig. 2a). Recently, we reported that inflammationinduced atrophy is caused by a dysregulation in protein homeostasis with decreased MyHC expression and increased UPS-dependent MyHC degradation [10]. Therefore, we investigated if IL-1 $\beta$ causes a reduction in $M y H C$ expression. $\mathrm{C} 2 \mathrm{C} 12$ myotubes were treated with IL-1 $\beta$ and vehicle, respectively, for $24 \mathrm{~h}$ and $M y h 2,4$, and 7 expression, encoding fast/type IIa, fast/type IIb and slow/type I MyHC, respectively, was quantitated by qRT-PCR (Fig. 2b). IL-1 $\beta$ treatment led to a decreased Myh2, Myh4, and Myh7 expression after $24 \mathrm{~h}$; whereas Dexa led to an increased Myh4 and Myh7 but not Myh2 expression (Fig. 2b). To test if IL-1 $\beta$ activates atrophy gene expression involved in MyHC degradation, we treated $\mathrm{C} 2 \mathrm{C} 12$ myotubes with $\mathrm{IL}-1 \beta$ for $2 \mathrm{~h}$ and quantitated Trim63 and Fbxo32 expression by qRT-PCR. IL-1 $\beta$ significantly increased Trim63 and Fbxo32 expression, indicating that MuRF1 and atrogin 1 are involved in IL- $1 \beta$-induced atrophy. Likewise, Dexa treatment increased Trim63 and Fbxo32 expression in myocytes (Fig. 2c). These data indicate that IL-1 $\beta$ causes a disturbed protein homeostasis contributing to IL-1 $\beta$ mediated atrophy.

\section{NIrp3 KO mice are protected against inflammation-induced atrophy}

At baseline, Nlrp3 KO were indistinguishable from WT mice and did not differ in body, liver, spleen, or skeletal muscle weights normalized to tibia length (Additional file 3A-C). To investigate whether or not Nlrp3 inflammasome-dependent IL-1 $\beta$ activation affects inflammation-induced atrophy, we subjected male Nlrp3 KO and WT mice to CLP (Nlrp3 $\mathrm{KO}, n=27$; WT, $n=33$ ) or sham surgery (Nlrp3 KO, $n=11$; WT, $n=16$ ), respectively. Compared to WT mice, significantly less Nlrp3 KO mice died after $96 \mathrm{~h}$ after CLP surgery 
a
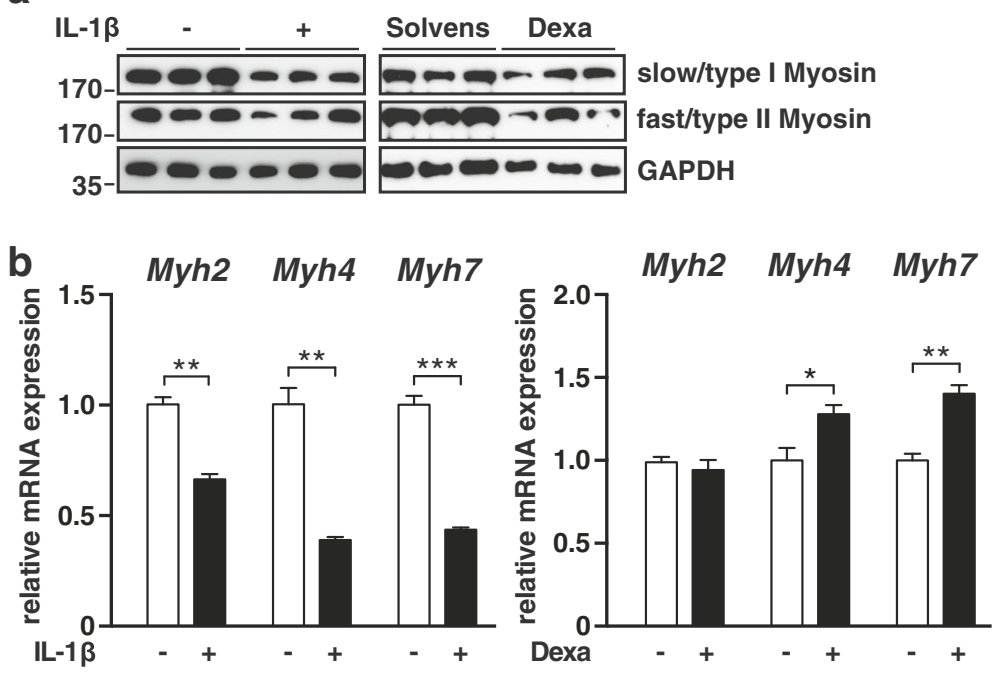

C
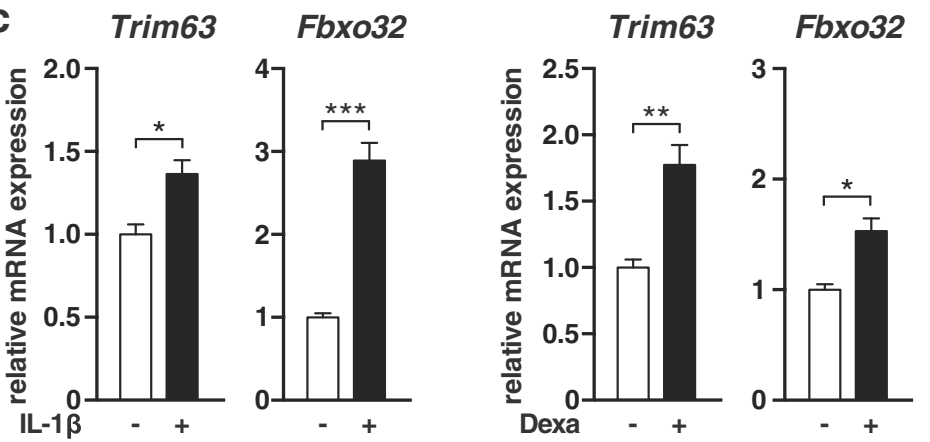

Fig. $2 \mathrm{LL}-1 \beta$ treatment induces Trim63 (MuRF1) and Fbxo32 (atrogin 1) gene expression and reduces slow and fast myosin heavy chain (MyHC) in $\mathrm{C} 2 \mathrm{C} 12$ myotubes. a C2C12 cells were differentiated for 8 days and treated with human recombinant $\mathrm{IL}-1 \beta(10 \mathrm{ng} / \mathrm{ml})$ for $72 \mathrm{~h}$. Dexamethasone $(10 \mu \mathrm{M} / \mathrm{ml})$ treatment was used as atrophy control. Western blot analysis with anti-myosin heavy chain $(\mathrm{MyHC})$ slow and anti-MyHC-fast antibody. $n=3$. GAPDH was used as loading control. $\mathbf{b}$ C2C12 cells were differentiated for 8 days and treated with human recombinant IL-1 $13(10 \mathrm{ng} / \mathrm{ml})$ for $24 \mathrm{~h}$. Dexamethasone $(10 \mu \mathrm{M} / \mathrm{ml})$ treatment was used as atrophy control. qRT-PCR analysis of myosin heavy chain (Myh) 2, Myh4, and Myh7 expression, mRNA expression was normalized to Gapdh. Data are presented as mean \pm SEM. $n=3 .{ }^{*} p \leq 0.05 ;{ }^{* *} p \leq 0.01$; ${ }^{* * *} p \leq 0.001$. c C2C12 cells were differentiated for 8 days and treated with human recombinant IL-1 $\beta$ $(10 \mathrm{ng} / \mathrm{ml})$ for $2 \mathrm{~h}$. Dexamethasone $(10 \mu \mathrm{M} / \mathrm{ml})$ treatment was used as atrophy control. qRT-PCR analysis of Trim63 (MuRF1) and Fbxo32 (atrogin 1) expression. mRNA expression was normalized to Gapdh. Data are presented as mean \pm SEM. $n=3 .{ }^{*} p \leq 0.05 ;{ }^{* *} p \leq 0.01 ;{ }^{* * *} p \leq 0.001$

(57.6 vs. $29.6 \%$; $p<0.05$ ) (Fig. 3a). Septic WT mice showed a reduction in body and liver weight and no change in spleen weight (Fig. 3b; Additional file 4A, B). In contrast, Nlrp3 KO did not lose body or liver weight, while spleen weight increased in these mice during sepsis (Fig. 3b; Additional file 4A, B). We investigated if absence of Nlrp3 affects muscular cytokine expression in sepsis. At baseline, Il6 expression was not different between Nlrp3 KO and WT in gastrocnemius/plantaris and tibialis anterior (Additional file 5A). CLP did not or only marginally induce muscular $I l 6$ expression in Nlrp3 KO compared to WT (Fig. 3c, d). Also, Il1b expression was not different between Nlrp3 KO and WT at baseline, and its expression was blunted in muscles of CLP-treated Nlrp3 KO compared to WT mice (Additional file 6A, B). CLP induced Nlrp3 expression in WT but not in Nlrp3 KO (Additional file 6C, D). Since conversion of pro- 


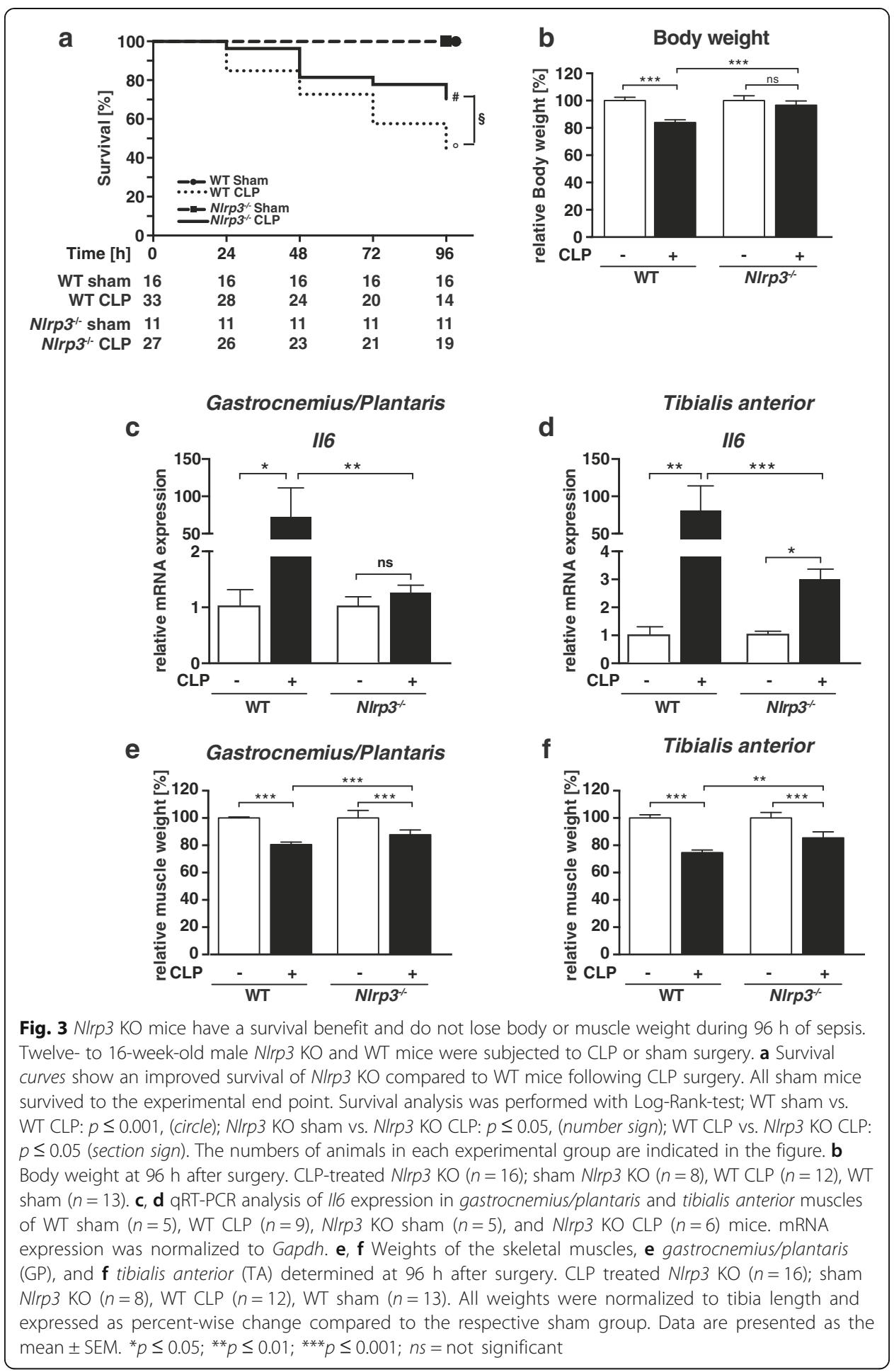

IL-1 $\beta$ to IL-1 $\beta$ depends on an intact Nlrp3 inflammasome $[14,24,25]$, we quantitated IL$1 \beta$ cytokine levels in the serum of Nlrp3 KO and WT. Already at baseline, IL-1 $\beta$ serum levels were reduced in Nlrp3 KO compared to WT (Additional file 6E). CLP significantly induced IL-1 $\beta$ serum levels in WT. This induction in IL-1 $\beta$ serum levels was greatly 
reduced in Nlrp3 KO (Additional file 6F). These data indicate that in sepsis muscular Il1b and $I l 6$ expression depend on Nlrp3.

Compared to WT sham, WT CLP mice showed a significant reduction in the weights of all muscles investigated $96 \mathrm{~h}$ after surgery. In contrast, the reduction of muscle mass of Nlrp3 KO CLP compared to Nlrp3 KO sham mice was less severe

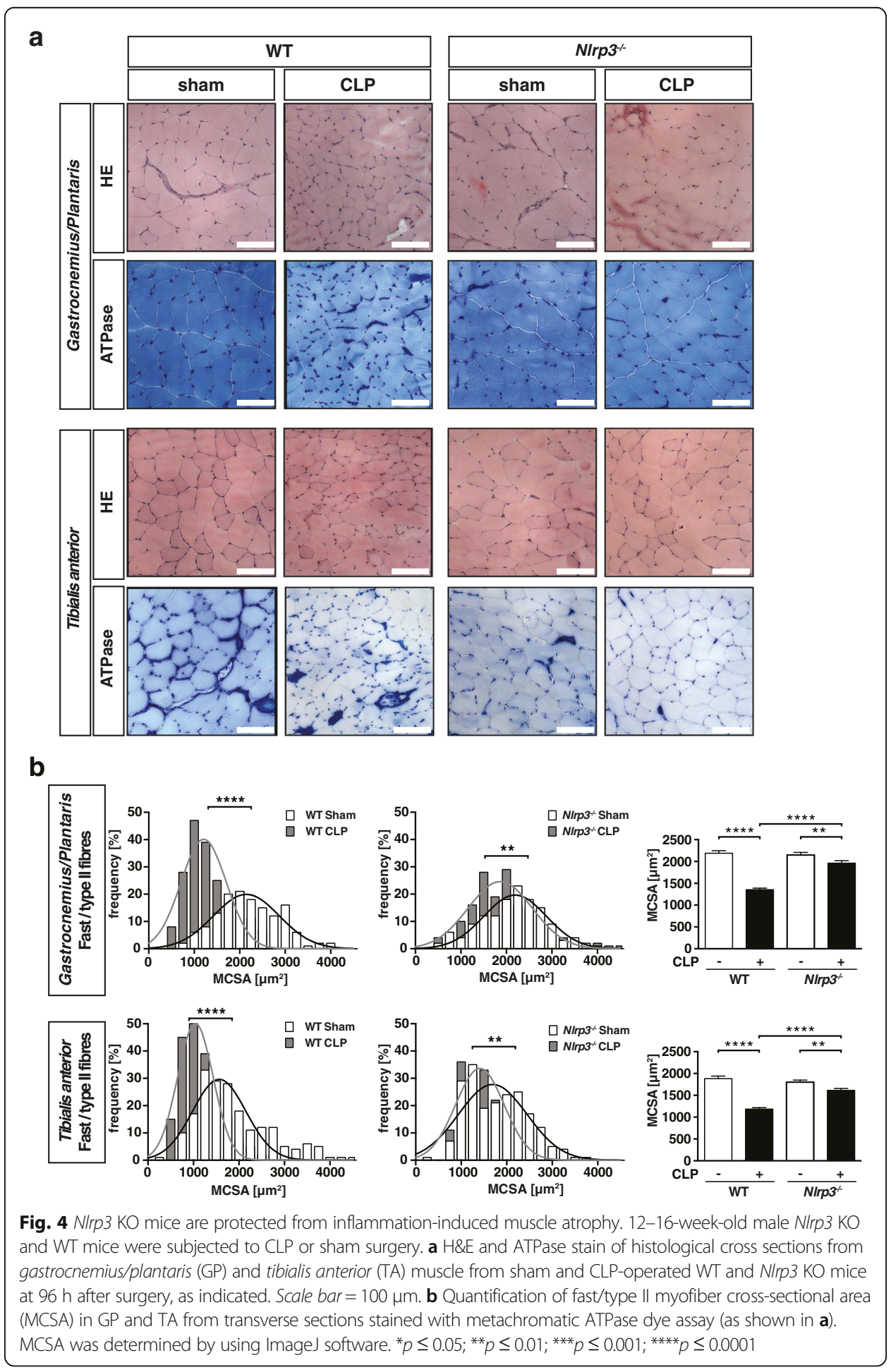


(Fig. 3e, f, Additional file 4C, D). These data indicate that Nlrp3 KO mice are protected against inflammation-induced atrophy. Since inflammation-induced atrophy predominantly affects fast-twitch fibers in critically ill patients [10], we analyzed atrophy of fast/type II fibers in gastrocnemius/plantaris and tibialis anterior muscles of Nlrp3 KO and WT after CLP. The histological pictures show that myofibers of WT but not of Nlrp3 KO CLP atrophied during sepsis (Fig. 4a). Accordingly, frequency distribution histograms of the myocyte cross sectional areas (MCSA) showed an increased number of smaller fast/type II fibers in both muscles of septic WT but not Nlrp3 KO leading to a leftward shift of the distribution curve (Fig. 4b). This atrophic response was attenuated in Nlrp3 KO compared to WT following sepsis as indicated by a less pronounced reduction in mean MCSA in septic Nlrp3 KO (Fig. 4b). These data indicate Nlrp3 contributes to fast/type II fiber atrophy in sepsis.

To test if inflammatory atrophy was accompanied by a reduction in MyHC, Western blot analysis was performed and showed that sepsis caused a reduction of slow and fast MyHC protein in gastrocnemius/plantaris and tibialis anterior of WT but not Nlrp3 KO (Fig. 5a). To elucidate if decreased myosin content was due to a reduction in MyHC gene expression, we quantitated Myh2, 4 and 7 by qRT-PCR. Inflammation caused a significant reduction in Myh2 and Myh7 gene expression in WT gastrocnemius/plantaris muscle (Fig. 5b). In contrast, Myh2 and Myh7 expression increased in Nlrp3 KO gastrocnemius/plantaris muscle during inflammation (Fig. 5b). Inflammation did not affect Myh4 gene expression. In the tibialis anterior muscle, Myh2 gene expression was regulated with the same trend as in gastrocnemius/plantaris, whereas Myh4 and Myh7 did not show a significant regulation (Additional file 7). To test if decreased myosin content was correlated with increased atrogene expression, we quantitated Trim63 and Fbxo32 expression in the muscle. Indeed, Trim63 and Fbxo32 expression were significantly increased in septic WT but remained unchanged in Nlrp3 KO muscles (Fig. 5c-f). Western blot analysis showed that MuRF1 protein expression was increased in gastrocnemius/plantaris of WT CLP but not in Nlrp3 KO CLP (Fig. 5a). These data indicate that decreased $M y h$ gene expression and its increased degradation contribute to inflammation-induced atrophy.

\section{Discussion}

ICUAW is a devastating disease warranting detailed mechanistic investigation [2, 45]. In our study, we found a close relationship between systemic inflammation in sepsis and muscle atrophy. We show that IL-1 $\beta$ signaling is present in myocytes and when activated leads to myocyte atrophy in vitro. Germline deletion of Nlrp3 in mice led to reduced IL-1 $\beta$ serum levels in response to inflammation and less inflammation-induced muscle atrophy in vivo. These data underscore the conclusion that during inflammation, skeletal muscle and myocytes are targeted by IL-1 $\beta$ to undergo atrophy. However, since Nlrp3 is ubiquitously expressed $[31,32]$, the observed reduction in IL- $1 \beta$ serum levels in response to inflammation was most likely caused by the absence of Nlrp3 in multiple cells, tissues, and organs and not only muscle. Nevertheless, our findings suggest Nlrp3 as target for treatment against inflammation-induced atrophy.

Based on earlier published work, we suggest that muscle contributes to inflammation and acute-phase response. Of note, the acute-phase response protein serum amyloid 


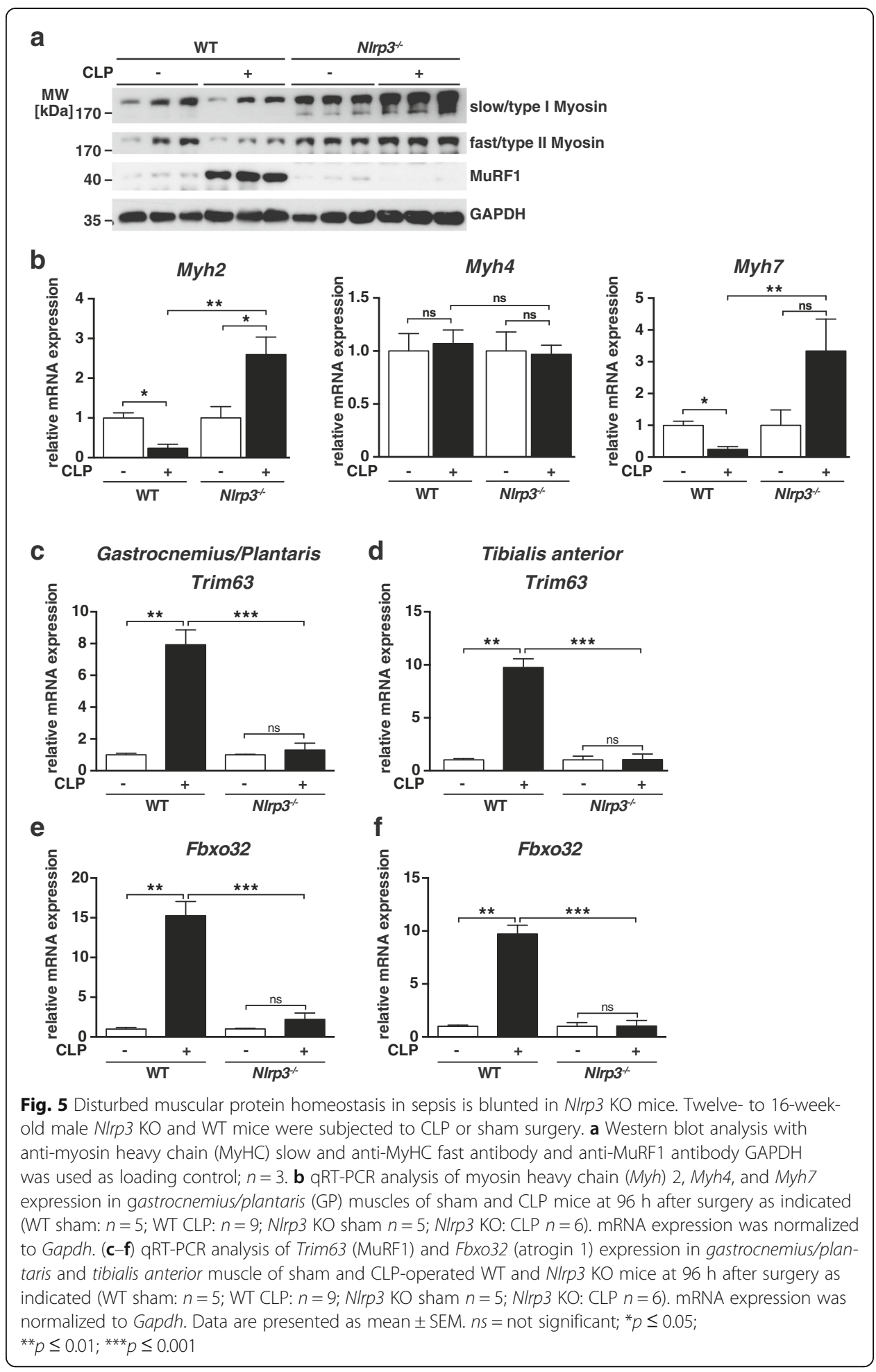

A1 (SAA1) was shown to be synthesized by and released from muscle of critically ill patients and septic mice [36]. SAA1 induces IL-1 $\beta$ expression [46] and secretion [47] and activates the Nlrp3 inflammasome in immune cells [46]. The Nlrp3 inflammasome is contained and active in $\mathrm{C} 2 \mathrm{C} 12$ myocytes [48]. IL-1 $\beta$ induces atrogene expression in myocytes [23]. Together, these data suggest feedback loops between IL-1 $\beta$, IL6, SAA1, 
and Nlrp3 during inflammation reinforcing muscle atrophy in critical illness. Here, we show that $I l 1 b$ and $I l 6$ as well as Nlrp3 expression are increased in muscles of septic mice. We show that the IL-1 $\beta$ signaling pathway is contained and active in myocytes in vitro. Based on these observations, it is possible that Nlrp3 KO mice have less overall inflammation during sepsis when compared to Nlrp3 WT animals and that not only decreased IL-1 $\beta$ levels but also reduced overall inflammation contributed to reduced muscle atrophy in septic Nlrp3 KO mice. However, since we did not perform a comprehensive analysis of inflammation in our mice, we cannot provide a definitive answer to this hypothesis.

We hypothesized that activation of the Nlrp3 inflammasome plays a role in inflammation-mediated muscle atrophy via activation of IL-1 $\beta$. The Nlrp3 inflammasome is activated by pathogen-associated molecular patterns [49] and host-derived molecules, such as DNA, which indicates cellular damage and cell death, so-called damage-associated molecular patterns [50]. Nlrp3 inflammasome could therefore contribute to both pathogen-associated immune responses and sterile-inflammation. We found that depletion of Nlrp3 in mice not only increases their survival in sepsis but also inhibits sepsis and inflammation-mediated muscle atrophy. We believe that this phenotype is predominantly caused by the missing conversion of pro-IL-1 $1 \beta$ to IL- $1 \beta$. We demonstrate that IL- $1 \beta$ induces atrophy presumably via the IL-1 signaling pathway leading to NF- $\mathrm{kB}$ activation and increased MuRF1 and atrogin 1 expression in vitro. This interpretation is in line with published work showing that IL-1 $\beta$ increases atrogene expression in vitro [23]. Likewise, decreased activation of IL-1 $\beta$ in Nlrp3 KO mice during sepsis resulted in decreased Il6 expression, which is a target of IL- $1 \beta$ and mediates atrophy $[36,51]$. We hypothesize that blockage of Nlrp3 inhibits sensing of pathogen and host signals, which is followed by inhibition of IL-1 $\beta$ - and IL-6dependent damage pathways resulting in better survival and reduced muscle atrophy.

IL- 6 and SAA1 mRNA and protein expression are increased in muscle of critically ill patients [7, 36]. These factors promote continuous inflammation and acute-phase response that in turn triggers ICUAW. We observed that IL-1 $\beta$ induces $I l 6$ and Nlrp3 expression in cultured myocytes. After $24 \mathrm{~h}$ of treatment, expression levels of both genes dropped. In contrast, in septic mice, the muscular expression of Il6 mRNA is still markedly increased after $96 \mathrm{~h}$ post CLP, reflecting the situation of critically ill patients. Our data add IL-1 $\beta$ and Nlrp3 as further cytokine network factors, highly expressed in the skeletal muscle during systemic inflammation. The observed differences between cultured myocytes and muscle tissue could be explained by the fact that a functional cytokine network relies on interacting organs rather than cell-to-cell communications within an isolated organ. This interpretation implies that the muscle, although itself an immune organ, requires interaction and feedback from other organs to fully respond to systemic inflammation. Taken together, during systemic inflammation, muscular expression of SAA1, IL-6, Nlrp3, and IL-1 $\beta$ is persistently elevated, which might contribute to atrophy.

An imbalanced muscular protein homeostasis plays a dominant role in muscle failure of critically ill patients $[4,10,38]$. Atrogin 1 and MuRF1 are key "atrogenes" in this process $[10,22,38,52]$. Our finding that atrogene expression was not increased in Nlrp3 KO indicates that atrogene expression is regulated by Nlrp3-dependent IL-1 $\beta$ activation. Muscle atrophy is accompanied by increased MyHC degradation and 
decreased MyHC expression [10]. Whereas sepsis led to a decreased Myh2 and Myh7 expression in muscle of WT, this effect was blunted in Nlrp3 KO. Because IL-1 $\beta$ treatment leads to decreased Myh2, Myh4, and Myh7 expression in myocytes, reduced muscular MyHC expression during sepsis might be caused by IL-1 $\beta$. Our data indicate that Nlrp3-mediated IL-1 $\beta$ activation may affect both major branches of protein homeostasis and therefore regulate $\mathrm{MyHC}$ synthesis via mRNA expression as well as UPS-mediated MyHC degradation.

\section{Conclusions}

We suggest that Nlrp3-mediated IL-1 $\beta$ activation in sepsis is a major pathogenic mechanism in inflammatory muscle atrophy. Inhibition of IL-1 $\beta$ could be useful to prevent ICUAW in critically ill patients. Since not only sepsis is associated with inflammation-induced muscle failure and increased IL-1 $\beta$ levels other forms of muscle atrophy might also profit from Nlrp3/IL-1 $\beta$ inhibition; for example, in patients with rheumatoid arthritis and inflammatory bowel disease. However, IL-1 $\beta$ is only one of many cytokines that are elevated during the cytokine storm in the acute phase of sepsis. It was shown that IL-1 $\beta, \mathrm{TNF}-\alpha$, and IFN- $\gamma$ were below detection limit in patients with septic shock admitted to an ICU [41]. In these patients, continuously high IL-6 serum levels were measured. IL-6 was not only negatively associated with muscular myosin contents, a marker for muscle atrophy, but also provoked atrophy in myocytes in vitro [41]. These data indicate that inhibition of multiple cytokines as well as its correct timing is important to reduce inflammation-induced atrophy. However, unlike during controlled conditions in animal experiments, the precise time point of sepsis onset in patients is often unknown which impedes such treatment decisions for the caring clinician. The key to a targeted therapy of inflammation-induced atrophy in sepsis is, therefore, a better characterization of the disease process, and we think that animal models are helpful in this regard.

\section{Additional files}

Additional file 1: Supplementary Materials and Methods. (DOCX 78 kb)

Additional file 2: Polymicrobial sepsis increases N/rp3, //1b, and $/ / 6$ expression in the muscle. Twelve-week-old male C57B16/J mice were subjected to cecal ligation and puncture (CLP) or sham surgery (sham), as indicated. (A) qRT-PCR analysis of N/rp3, IL-1 $\beta$, and $/ 16$ expression in gastrocnemius/plantaris (GP) and (B) tibialis anterior (TA) muscles of sham $(n=5)$ and CLP $(n=5)$ mice 4 days after surgery. mRNA expression was normalized to Gapdh. Data are presented as mean \pm SEM. ${ }^{*} p<0.05,{ }^{* *} p<0.01$, ${ }^{* *} p<0.001$. (EPS $1161 \mathrm{~kb}$ )

Additional file 3: Body and organ weights of N/rp3 KO and WT mice were indistinguishable at baseline. Weights of body (A), liver and spleen (B), and muscle (C); gastrocnemius/plantaris (GP), tibialis anterior (TA), soleus (Sol) and extensor digitorum longus (EDL)); NIrp3 KO $(n=6) ; \mathrm{WT}(n=6)$. All weights were normalized to tibia length and expressed as percent wise change compared to WT. Animals were 12-16-week-old males. Data are presented as the mean \pm SEM. $\mathrm{ns}=$ not significant. (EPS $1175 \mathrm{~kb}$ )

Additional file 4: Septic Nlrp3 KO mice show no decrease in liver weight but an increase in spleen weight. Twelve- to 16-week-old male NIrp3 KO and WT mice were subjected to CLP or sham surgery. Weights were determined at $96 \mathrm{~h}$ after surgery. (A) Liver and (B) spleen weight. (C, D) Weights of the skeletal muscles (C) soleus (Sol) and (D) extensor digitorum longus (EDL) (WT sham $(n=13)$, WT CLP $(n=12)$, N/rp3 KO sham $(n=8)$, Nlrp3 KO CLP $(n=16)$ ). All weights were normalized to tibia length and expressed as percent wise change compared to the respective sham group. Data are presented as the mean \pm SEM. ns = not significant. ${ }^{*} p<0.05 ;{ }^{* *} p<0.01 ;{ }^{* * *} p<0.001$. (EPS $1427 \mathrm{~kb}$ )

Additional file 5: Baseline muscular $1 / 6$ and $/ 116$ expression in N/rp3 KO and WT mice. qRT-PCR analysis of (A) $/ 16$ and (B) ILIb expression in gastrocnemius/plantaris (GP) and tibialis anterior (TA) muscles as indicated. N/rp3 KO $(n=6)$ and WT $(n=6)$. mRNA expression was normalized to Gapdh. Data are presented as the mean \pm SEM. $\mathrm{ns}=$ not significant. (EPS $1144 \mathrm{~kb}$ ) 
Additional file 6: Inflammation-induced increase in muscular 116 and $1 / 16$ expression as well as serum IL-1 $\beta$ levels are blunted in N/rp3 KO mice. Twelve- to 16-week-old male N/rp3 KO and WT mice were subjected to CLP or sham surgery, as indicated. At $96 \mathrm{~h}$ after surgery, analyses were performed. (A-D) qRT-PCR analysis of (A, B) $1 / 16$ and (C, D) Nlrp3 expression in gastrocnemius/plantaris (GP) and tibialis anterior (TA) muscles of WT sham

$(n=5)$, WT CLP $(n=9)$, Nirp3 KO sham $(n=5)$, and NIrp3 KO CLP $(n=6)$ mice. mRNA expression was normalized to Gapdh. (E, F) Serum IL-1 $\beta$ was determined in WT and NIrp3 KO mice using the Abcam kit according to the manufacturer's protocol. (E) Serum IL-1 $\beta$ concentration at baseline. (F) Serum IL-1 $\beta$ concentration in Sham and CLP mice. WT-sham $(n=15)$, WT-CLP $(n=12)$, Nlrp3 KO-sham $(n=14)$, N/rp3 KO-CLP $(n=14)$. Data are presented as mean \pm SEM. ns, not significant; ${ }^{* *} p \leq 0.01 ;{ }^{* * *} p \leq 0.001$. n.d. $=$ not detected. (EPS $1443 \mathrm{~kb}$ )

Additional file 7: Inflammation-induced decrease of myosin heavy chain gene expression is blunted in N/rp3 KO mice. Twelve- to 16-week-old male NIrp3 KO and WT mice were subjected to CLP or sham surgery. QRT-PCR analysis of myosin heavy chain (Myh) 2, Myh4, and Myh7 expression in tibialis anterior (TA) muscles of sham $(n=5)$ and CLP $(n=5)$ mice at $96 \mathrm{~h}$ after surgery as indicated (WT sham: $n=5$; WT CLP: $n=9$; NIrp3 KO sham $n=5$; NIrp3 KO: CLP $n=6$ ). mRNA expression was normalized to Gapdh. Data are presented as mean \pm SEM. ns, not significant; ${ }^{* *} p \leq 0.01$. (EPS $\left.1369 \mathrm{~kb}\right)$

\section{Abbreviations}

CLP: Cecal ligation and puncture model of polymicrobial sepsis; Fbxo32: F-box only protein 32 (mouse gene encoding atrogin 1); ICU: Intensive care unit; ICUAW: Intensive care unit (ICU)-acquired weakness; IL: Interleukin; MCSA: Myocyte cross-sectional area; MuRF: Muscle really interesting new gene (RING)-finger containing protein; Myh: Myosin heavy chain; Nlrp3: Nucleotide-binding oligomerization domain (NOD), leucine rich repeat and pyrin domain containing 3 (mouse gene encoding Nalp3); qRT-PCR: Quantitative real-time polymerase chain reaction; Trim63: Tripartite motif containing 63 (mouse gene encoding MuRF1)

\section{Acknowledgements}

We thank Aubry Tardivel and Nicolas Fasel of the University of Lausanne for providing NIrp3 KO mice. We thank Mihail Todiras for the helpful discussions, logistical support, and hospitality.

\section{Funding}

JF received grants from the Deutsche Forschungsgemeinschaft (FI 965/4-1, Fl 965/5-1, Fl 965/5-2). FCL and JF received funding from the Experimental and Clinical Research Center and the Berlin Institute of Health. FR and JF received funding from Ernst und Berta Grimmke Stiftung.

\section{Availability of data and materials}

The datasets during and/or analyzed during the current study are available from the corresponding author on reasonable request.

\section{Authors' contributions}

$\mathrm{NH}, \mathrm{MK}, \mathrm{FR}, \mathrm{KB}, \mathrm{SS}, \mathrm{HS}$, FCL, and JF designed and analyzed the experiments, discussed the data, and prepared the manuscript. All authors read and approved the final manuscript.

\section{Competing interests}

The authors declare that they have no competing interests.

\section{Consent for publication}

Not applicable.

\section{Ethics approval}

Animal procedures were performed in accordance with the guidelines of the Max-Delbrück Center for Molecular Medicine, were approved by the Landesamt für Gesundheit und Soziales, Berlin, Germany (G207/13, G129/12), and followed the "Principles of Laboratory Animal Care" (NIH publication No. 86-23, revised 1985) and the current version of German Law on the Protection of Animals.

\section{Author details}

'Experimental and Clinical Research Center (ECRC), Charité-Universitätsmedizin Berlin, Max Delbrück Center (MDC) for Molecular Medicine in the Helmholtz Association, Berlin, Germany. ${ }^{2}$ Department of Cardiology, Heart Center Brandenburg and Medical University Brandenburg (MHB), Bernau, Germany. ${ }^{3}$ Department of Cardiology and Pneumology, Medical University Brandenburg (MHB), Brandenburg, Germany. ${ }^{4}$ Berlin Institute of Health $(B \mid H)$, Kapelle-Ufer 2, 10117 Berlin, Germany. ${ }^{5}$ ZIK Septomics, Host Septomics, Jena, Germany. ${ }^{6}$ Integrated Research and Treatment Center-Center for Sepsis Control and Care (CSCC), Jena University Hospital, Jena, Germany.

Received: 22 July 2016 Accepted: 29 December 2016

Published online: 17 January 2017

\section{References}

1. Bierbrauer J, Koch S, Olbricht C, Hamati J, Lodka D, Schneider J, Luther-Schröder A, Kleber C, Faust K, Wiesener S, Spies CD, Spranger J, Spuler S, Fielitz J, Weber-Carstens S (2012) Early type II fiber atrophy in intensive care unit patients with nonexcitable muscle membrane. Crit Care Med 40:647-650

2. Bolton CF (1993) Neuromuscular complications of sepsis. Intensive Care Med 19(Suppl 2):S58-S63 
3. Lefaucheur JP, Nordine T, Rodriguez P, Brochard L (2006) Origin of ICU acquired paresis determined by direct muscle stimulation. J Neurol Neurosurg Psychiatry 77:500-506

4. Puthucheary ZA, Rawal J, McPhail M, Connolly B, Ratnayake G, Chan P, Hopkinson NS, Phadke R, Padhke R, Dew T, Sidhu PS, Velloso C, Seymour J, Agley CC, Selby A, Limb M, Edwards LM, Smith K, Rowlerson A, Rennie MJ, Moxham J, Harridge SDR, Hart N, Montgomery HE (2013) Acute skeletal muscle wasting in critical illness. JAMA 310:1591-1600

5. De Jonghe B, Sharshar T, Lefaucheur J-P, Authier F-J, Durand-Zaleski I, Boussarsar M, Cerf C, Renaud E, Mesrati F, Carlet J, Raphaël J-C, Outin H, Bastuji-Garin S, Groupe de Réflexion et d'Etude des Neuromyopathies en R (2002) Paresis acquired in the intensive care unit: a prospective multicenter study. JAMA 288:2859-2867

6. Herridge MS, Tansey CM, Matté A, Tomlinson G, Diaz-Granados N, Cooper A, Guest CB, Mazer CD, Mehta S, Stewart TE, Kudlow P, Cook D, Slutsky AS, Cheung AM, Canadian Critical Care Trials G (2011) Functional disability 5 years after acute respiratory distress syndrome. N Engl J Med 364:1293-1304

7. Weber-Carstens S, Deja M, Koch S, Spranger J, Bubser F, Wernecke KD, Spies CD, Spuler S, Keh D (2010) Risk factors in critical illness myopathy during the early course of critical illness: a prospective observational study. Crit Care 14:R119

8. Winkelman C (2010) The role of inflammation in ICU-acquired weakness. Crit Care 14:186

9. Levine S, Nguyen T, Taylor N, Friscia ME, Budak MT, Rothenberg P, Zhu J, Sachdeva R, Sonnad S, Kaiser LR, Rubinstein NA, Powers SK, Shrager JB (2008) Rapid disuse atrophy of diaphragm fibers in mechanically ventilated humans. N Engl J Med 358:1327-1335

10. Wollersheim T, Woehlecke J, Krebs M, Hamati J, Lodka D, Luther-Schroeder A, Langhans C, Haas K, Radtke T, Kleber C, Spies C, Labeit S, Schuelke M, Spuler S, Spranger J, Weber-Carstens S, Fielitz J (2014) Dynamics of myosin degradation in intensive care unit-acquired weakness during severe critical illness. Intensive Care Med 40:528-538

11. Klaude M, Mori M, Tjäder I, Gustafsson T, Wernerman J, Rooyackers O (2012) Protein metabolism and gene expression in skeletal muscle of critically ill patients with sepsis. Clin Sci (Lond) 122:133-142

12. Constantin D, McCullough J, Mahajan RP, Greenhaff PL (2011) Novel events in the molecular regulation of muscle mass in critically ill patients. J Physiol Lond 589:3883-3895

13. Helliwell TR, Wilkinson A, Griffiths RD, McClelland P, Palmer TE, Bone JM (1998) Muscle fibre atrophy in critically ill patients is associated with the loss of myosin filaments and the presence of lysosomal enzymes and ubiquitin. Neuropathol Appl Neurobiol 24:507-517

14. Dinarello CA (2005) Interleukin-1 beta. Crit Care Med 33:S460-S462

15. Pruitt JH, Copeland EM, Moldawer LL (1995) Interleukin-1 and interleukin-1 antagonism in sepsis, systemic inflammatory response syndrome, and septic shock. Shock 3:235-251

16. Sullivan JS, Kilpatrick L, Costarino AT, Lee SC, Harris MC (1992) Correlation of plasma cytokine elevations with mortality rate in children with sepsis. J Pediatr 120:510-515

17. Cannon JG, Tompkins RG, Gelfand JA, Michie HR, Stanford GG, van der Meer JW, Endres S, Lonnemann G, Corsetti J, Chernow B (1990) Circulating interleukin-1 and tumor necrosis factor in septic shock and experimental endotoxin fever. J Infect Dis 161:79-84

18. Jean-Baptiste E (2007) Cellular mechanisms in sepsis. J Intensive Care Med 22:63-72

19. van Deuren M (1994) Kinetics of tumour necrosis factor-alpha, soluble tumour necrosis factor receptors, interleukin 1beta and its receptor antagonist during serious infections. Eur J Clin Microbiol Infect Dis 13(Suppl 1):S12-S16

20. Salkowski CA, Detore G, Franks A, Falk MC, Vogel SN (1998) Pulmonary and hepatic gene expression following cecal ligation and puncture: monophosphoryl lipid A prophylaxis attenuates sepsis-induced cytokine and chemokine expression and neutrophil infiltration. Infect Immun 66:3569-3578

21. Llovera M, Carbó N, López-Soriano JN, García-Martínez C, Busquets S, Alvarez B, Agell N, Costelli P, López-Soriano FJ, Celada A, Argilés JM (1998) Different cytokines modulate ubiquitin gene expression in rat skeletal muscle. Cancer Lett 133:83-87

22. Bodine SC, Latres E, Baumhueter S, Lai VK, Nunez L, Clarke BA, Poueymirou WT, Panaro FJ, Na E, Dharmarajan K, Pan ZQ, Valenzuela DM, DeChiara TM, Stitt TN, Yancopoulos GD, Glass DJ (2001) Identification of ubiquitin ligases required for skeletal muscle atrophy. Science 294:1704-1708

23. Li W, Moylan JS, Chambers MA, Smith J, Reid MB (2009) Interleukin-1 stimulates catabolism in C2C12 myotubes, Am J Physiol Cell Physiol 297:C706-C714

24. Afonina Inna S, Müller C, Martin Seamus J, Beyaert R (2015) Proteolytic processing of interleukin-1 family cytokines: variations on a common theme. Immunity 42:991-1004

25. Cerretti DP, Kozlosky CJ, Mosley B, Nelson N, Van Ness K, Greenstreet TA, March CJ, Kronheim SR, Druck T, Cannizzaro LA (1992) Molecular cloning of the interleukin-1 beta converting enzyme. Science 256:97-100

26. Dinarello CA (2009) Immunological and inflammatory functions of the interleukin-1 family. Annu Rev Immunol 27: $519-550$

27. Dinarello CA, Cannon JG, Wolff SM, Bernheim HA, Beutler B, Cerami A, Figari IS, Palladino MA, O'Connor JV (1986) Tumor necrosis factor (cachectin) is an endogenous pyrogen and induces production of interleukin 1. J Exp Med 163:1433-1450

28. Dinarello CA, Ikejima T, Warner SJ, Orencole SF, Lonnemann G, Cannon JG, Libby P (1987) Interleukin 1 induces interleukin 1. I. Induction of circulating interleukin 1 in rabbits in vivo and in human mononuclear cells in vitro. J Immunol 139:1902-1910

29. Gross O, Thomas CJ, Guarda G, Tschopp J (2011) The inflammasome: an integrated view. Immunol Rev 243:136-151

30. Lamkanfi M, Dixit VM (2012) Inflammasomes and their roles in health and disease. Annu Rev Cell Dev Biol 28:137-161

31. Hotchkiss RS, Karl IE (2003) The pathophysiology and treatment of sepsis. N Engl J Med 348:138-150

32. Schroder K, Tschopp J (2010) The inflammasomes. Cell 140:821-832

33. Brigelius-Flohé R, Banning A, Kny M, Böl G-F (2004) Redox events in interleukin-1 signaling. Arch Biochem Biophys 423:66-73

34. Rawat R, Cohen TV, Ampong B, Francia D, Henriques-Pons A, Hoffman EP, Nagaraju K (2010) Inflammasome upregulation and activation in dysferlin-deficient skeletal muscle. Am J Pathol 176:2891-2900

35. Martinon F, Petrilli V, Mayor A, Tardivel A, Tschopp J (2006) Gout-associated uric acid crystals activate the NALP3 inflammasome. Nature 440:237-241 
36. Langhans C, Weber-Carstens S, Schmidt F, Hamati J, Kny M, Zhu X, Wollersheim T, Koch S, Krebs M, Schulz H, Lodka D, Saar K, Labeit S, Spies C, Hubner N, Spranger J, Spuler S, Boschmann M, Dittmar G, Butler-Browne G, Mouly V, Fielitz J (2014) Inflammation-induced acute phase response in skeletal muscle and critical illness myopathy. PLoS ONE 9:e92048

37. Rittirsch D, Huber-Lang MS, Flierl MA, Ward PA (2009) Immunodesign of experimental sepsis by cecal ligation and puncture. Nat Protoc 4:31-36

38. Schmidt F, Kny M, Zhu X, Wollersheim T, Persicke K, Langhans C, Lodka D, Kleber C, Weber-Carstens S, Fielitz J (2014) The E3 ubiquitin ligase TRIM62 and inflammation-induced skeletal muscle atrophy. Crit Care 18:545

39. Yaffe D, Saxel O (1977) Serial passaging and differentiation of myogenic cells isolated from dystrophic mouse muscle. Nature 270:725-727

40. Blau HM, Pavlath GK, Hardeman EC, Chiu CP, Silberstein L, Webster SG, Miller SC, Webster C (1985) Plasticity of the differentiated state. Science 230:758-766

41. van Hees HW, Schellekens WJ, Linkels M, Leenders F, Zoll J, Donders R, Dekhuijzen PN, van der Hoeven JG, Heunks LM (2011) Plasma from septic shock patients induces loss of muscle protein. Crit Care 15:R233

42. Passey SL, Bozinovski S, Vlahos R, Anderson GP, Hansen MJ (2016) Serum amyloid A induces Toll-like receptor 2-dependent inflammatory cytokine expression and atrophy in C2C12 skeletal muscle myotubes. PLOS ONE 11:e0146882

43. Hoene M, Runge H, Haring HU, Schleicher ED, Weigert C (2013) Interleukin-6 promotes myogenic differentiation of mouse skeletal muscle cells: role of the STAT3 pathway. Am J Physiol Cell Physiol 304:C128-C136

44. Zhu X, Kny M, Schmidt F, Hahn A, Wollersheim T, Kleber C, Weber-Carstens S, Fielitz J, (2016) Secreted frizzledrelated protein 2 and inflammation-induced skeletal muscle atrophy. Crit Care Med. [Epub ahead of print]

45. Callahan LA, Supinski GS (2009) Sepsis-induced myopathy. Crit Care Med 37:S354-S367

46. Niemi K, Teirilä L, Lappalainen J, Rajamäki K, Baumann MH, Öörni K, Wolff H, Kovanen PT, Matikainen S, Eklund KK (2011) Serum amyloid A activates the NLRP3 inflammasome via P2X7 receptor and a cathepsin B-sensitive pathway. J Immunol 186:6119-6128

47. Yu N, Liu S, Yi X, Zhang S, Ding Y (2015) Serum amyloid A induces interleukin-1 $\beta$ secretion from keratinocytes via the NACHT, LRR and PYD domains-containing protein 3 inflammasome. Clin Exp Immunol 179:344-353

48. Cho K-A, Kang PB (2015) PLIN2 inhibits insulin-induced glucose uptake in myoblasts through the activation of the NLRP3 inflammasome. Int J Mol Med 36:839-844

49. Kanneganti T-D, Ozören N, Body-Malapel M, Amer A, Park J-H, Franchi L, Whitfield J, Barchet W, Colonna M, Vandenabeele P, Bertin J, Coyle A, Grant EP, Akira S, Núñez G (2006) Bacterial RNA and small antiviral compounds activate caspase-1 through cryopyrin/Nalp3. Nature 440:233-236

50. Jin C, Flavell RA (2010) Molecular mechanism of NLRP3 inflammasome activation. J Clin Immunol 30:628-631

51. LeMay LG, Otterness IG, Vander AJ, Kluger MJ (1990) In vivo evidence that the rise in plasma IL 6 following injection of a fever-inducing dose of LPS is mediated by IL 1 beta. Cytokine 2:199-204

52. Lecker SH, Jagoe RT, Gilbert A, Gomes M, Baracos V, Bailey J, Price SR, Mitch WE, Goldberg AL (2004) Multiple types of skeletal muscle atrophy involve a common program of changes in gene expression. FASEB J 18:39-51

\section{Submit your manuscript to a SpringerOpen ${ }^{\circ}$ journal and benefit from:}

- Convenient online submission

- Rigorous peer review

- Immediate publication on acceptance

- Open access: articles freely available online

- High visibility within the field

Retaining the copyright to your article 